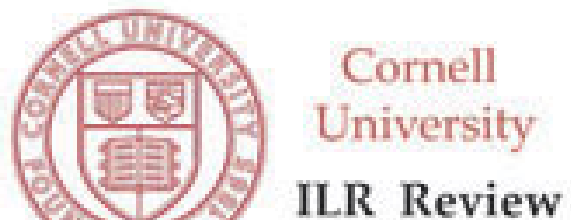

Physician Supply Behavior in the Short Run

Author(s): Frank A. Sloan

Source: Industrial and Labor Relations Review, Vol. 28, No. 4 (Jul., 1975), pp. 549-569

Published by: Cornell University, School of Industrial \& Labor Relations

Stable URL: http://www.jstor.org/stable/2521651

Accessed: 29/07/2009 01:55

Your use of the JSTOR archive indicates your acceptance of JSTOR's Terms and Conditions of Use, available at http://www.jstor.org/page/info/about/policies/terms.jsp. JSTOR's Terms and Conditions of Use provides, in part, that unless you have obtained prior permission, you may not download an entire issue of a journal or multiple copies of articles, and you may use content in the JSTOR archive only for your personal, non-commercial use.

Please contact the publisher regarding any further use of this work. Publisher contact information may be obtained at http://www.jstor.org/action/showPublisher?publisherCode=cschool.

Each copy of any part of a JSTOR transmission must contain the same copyright notice that appears on the screen or printed page of such transmission.

JSTOR is a not-for-profit organization founded in 1995 to build trusted digital archives for scholarship. We work with the scholarly community to preserve their work and the materials they rely upon, and to build a common research platform that promotes the discovery and use of these resources. For more information about JSTOR, please contact support@jstor.org. 


\title{
PHYSICIAN SUPPLY BEHAVIOR IN THE SHORT RUN
}

\author{
FRANK A. SLOAN
}

$\mathrm{M}$ ANY individuals have recently expressed concern over the rising cost of medical care and other barriers to medical services encountered even by those willing and able to pay. Among the solutions that have been proposed are policies directed toward increasing the effective supply of physicians' services, such as programs to expand medical school enrollments and to promote increased physician productivity through the development of new types of health occupations and more efficient organizational forms of health care delivery.

This study analyzes determinants of two dimensions of the supply of physi-

\footnotetext{
This study analyzes determinants of two dimensions of the supply of physicians' services: the number of hours physicians work per week and the number of weeks they work per year. Using data from the 1960 and 1970 Public Use Samples of the census, the author demonstrates that in the short run physician supply is not greatly affected by variations in professional income, although that supply is affected by factors such as the physician's nonprofessional income, age, and sex and by whether the physician is self-employed or on salary. The author discusses the implications of these findings for government health insurance and other public policy issues.

Frank A. Sloan is Associate Professor of Economics and Community Health and Family Medicine, University of Florida. $\mathrm{He}$ wishes to thank Jane Haugh, Jerry Jackson, and Oswaldo Sarraff for computational assistance and John Lorant, Bruce Steinwald, and Stephen Vahovich for comments on an earlier draft. This research was supported in part by a grant from the Bureau for Health Services Research and Development, Department of Health, Education, and Welfare, to the University of Florida.-EDrToR
}

cians' services: the number of hours physicians work per week and the number of weeks they work per year. Although no government program has been formulated specifically to influence those two dimensions of physician supply, many existing or proposed programs may nevertheless have an unintended or indirect effect on them. For example, if physicians' supply curves are backward-bending, price control programs lowering physician earnings per unit of effort may actually increase the aggregate supply of physicians' services, whereas programs such as Medicare and Medicaid or impending national health insurance, by improving physicians' potential total earnings, may inadvertently lower total physician input. If, conversely, supply curves have a zero or positive slope, price control will either have no effect or will decrease total input, and government insurance plans will either have no impact or will increase the physician time input.

Data for the study are from physicians' records randomly selected from the 1960 and 1970 Public Use Samples (a one percent sample) of the U.S. Census of Population. This source provides data on the number of weeks physicians worked in 1959 and in 1969 and the number of hours worked during "reference" weeks in March 1960 and March 1970. The samples also contain detailed data on physician income 
from employment and nonemployment sources, type of employer, and various personal characteristics-for example, each physician's sex, age, birthplace, and marital and health status. Attributes of the physician's spouse and children are likewise recorded. The response rate was virtually 100 percent, thus eliminating the dangers of nonresponse bias that plague other surveys of physicians.

\section{Analytic Framework}

The theory of the household provides the most appropriate analytic framework for a study of this nature, but that theory cannot be used uncritically. The majority of physicians are self-employed and thus serve in roles as both household decision makers and owner-managers of small firms. The traditional theory of the household assumes that the work-leisure choice is made on the basis of a fixed wage rate, but the selfemployed physician, particularly if he is among the majority working in solo practice or in a small group, probably does not face a fixed wage. Instead, his wage (that is, his earnings per unit of time), decreases as his hours of work increase.

The wage is expected to fall for two reasons. First, since the physician is the principal input to his practice, his marginal product depends on his hours of work. Where large numbers of individuals are employed in an input category, the hours decision of a single individual has only a minor effect on the marginal product for the input category as a whole, but the physician often works alone or in a small group. Estimates show the effect of hours of work on the marginal product of the physician input to be of sufficient size, albeit small, to warrant consideration. ${ }^{1}$ Second, if the physician sets fees for his services, the price charged varies inversely with the quantity he sells and therefore also inversely with the number of hours he works. For both reasons, ordinary least squares estimates of the impact of wages on the physician time input will be biased in the negative direction.

Aside from these two expected relationships between the physician's time input and his wage, errors-in-variables may also produce a negatively biased estimate of the supply response to wages unless precautions are taken. Because direct measures of the physician wage are not available, physician-wage variables have been constructed from the following information:

E: earnings from medical practice in the year preceding the census.

$\mathrm{W}$ : weeks of work in the year preceding the census.

$\mathrm{H}$ : hours of work in the week preceding the census.

Weekly and hourly wages constructed from these data are the equivalent of $\mathrm{E} / \mathrm{W}$ and $\mathrm{E} /(\mathrm{W} \cdot \mathrm{H})$ respectively. Any errors in measuring the dependent sup-

\footnotetext{
1For a more detailed theoretical argument and evidence on the physician's marginal product, see Frank A. Sloan, "A Microanalysis of Physicians' Hours of Work Decisions," in Mark Perlman, ed., The Economics of Health and Medical Care (London: MacMillan, 1974), pp. 302-325. The evidence on marginal product is derived from Uwe E. Reinhardt, "A Product Function for Physician Services," The Review of Economics and Statistics, Vol. 59, No. 1 (February 1972), pp. 55-66. For further discussion of problems associated with estimating a supply curve for self-employed persons, see E. Odgers Olsen, "Utility and Profit Maximization by an OwnerManager," Southern Economic Journal, Vol. 39, No. 3 (January 1973), pp. 389-395, and Terrence J. Wales, "Estimation of a Labor Supply Curve for Self-Employed Business Proprietors," International Economic Review, Vol. 14, No. 1 (February 1973), pp. 69-80.
} 
ply variables, $\mathrm{W}$ and $\mathrm{H}$, will obviously be repeated in the denominators of the computed wages for weeks and hours; thus there is again a negative bias if the ordinary least squares technique is used. ${ }^{2}$

To reduce these potential biases, an instrumental variable technique, in which the physician wage is specified to be a function of several exogenous variables, is employed. This technique captures variation in wages from sources other than the time the physician devotes to his practice. Also, if the instruments are properly selected, the technique is a solution to the errors-invariables problem. Although the wage equations described below were therefore developed to improve the supply analysis-that is, to provide a more accurate measure of wages as an independent variable-it will be seen that the sources of variation in physicians' earnings revealed by the wage equations are of interest in their own right.

\section{Wage Equation Specification}

Two wage equations will be estimated, in which physician earnings per week and per hour are the dependent variables. Both earnings measures are net of practice expenses, but before taxes. Both wage equations contain the same explanatory variables, which may be classified into four categories: (1) age and experience, (2) discrimination, (3) employment type, and (4) area characteristics. All these variables are defined in the Appendix, where their means and standard deviations are also presented.

\footnotetext{
2The errors-in-variables problem is discussed more fully in David H. Greenberg, Problems of Model Specification and Measurement: The Labor Supply Function (Santa Monica, Calif.: Rand Corp., 1972 (R-7085-EDA)) .
}

Relationships among age, experience, and earnings are well known. Studies of life-cycle patterns report an inverted asymmetric U-shaped relationship among these variables: earnings rise rapidly in the early working years and decline somewhat as retirement age approaches. ${ }^{3}$ Unfortunately, the census source contains little information on experience. The only direct evidence is from the 1970 census, which requests the respondent's occupation as of 1965 . Newly established physicians are therefore distinguished from their colleagues by the variable NMD (=1 if the respondent was not a physician in 1965), but of course that measure reveals nothing about the work experience of most physicians in the sample. Age, however, is a reasonably good proxy for experience, ${ }^{4}$ and for that reason the four age dummy variables defined in the Appendix are included. These dummies test the earnings of physicians younger than sixty-five against the sixty-five to sixty-nine age group. The following

\footnotetext{
3Giora Hanoch, "Personal Earnings and Investment in Schooling." (Ph.D. dissertation, University of Chicago, 1965). Julie DaVanzo, Dennis DeTray, and David H. Greenberg, Estimating Labor Supply Response: A Sensitivity Analysis (Santa Monica, Calif.: Rand Corp., 1973 (R-1372OEO)). The dependent variable in the wage equations here is not annual earnings, as it is in many studies. A decrease in the amount of labor supplied is generally one reason for the decline in earnings as retirement age approaches. By contrast, our wage measures principally reflect factors related to productivity per week or per hour.

${ }^{4}$ Mincer obtains an indirect estimate of laborforce experience by assigning a value to respondent's age of entry into the labor force on the basis of his years of schooling completed and subtracting this number from his current age. Since all physicians report the same number of years of schooling, this approach is not feasible for the present study. See Jacob Mincer, "Schooling, Experience, and Earnings," mimeographed (New York: National Bureau of Economic Research, 1972).
} 
categories are excluded from the sample: physicians under age thirty (Al), because virtually all MDs in this age group are still in training; those age seventy and over; those who reported no work hours during the week before the census; and those who reported no weeks worked during the year before the census.

Other measures of experience are included to test the expectation that although physicians may relocate to improve lifetime earnings, the newcomer in an area will probably have lower earnings initially than his colleagues who are more established in that area. Three variables represent physician experience in his current geographic area: M1 (=1) if the physician lived in another county five years before the census; M2 $(=1)$ if he then lived in another state; and M3 (=1) if he then lived abroad.

Four discrimination variables are included in the wage-generating equation. Women are distinguished by the variable SEX $(=1$ if the physician is female). The variable RACEN ( $=1$ if the physician is black) is included to reflect both poor medical educational opportunities available to blacks until recently and discrimination against the practicing black physician. The sign of RACEN's coefficient is expected to be negative. Variables included to take into account the impact of a physician's being born outside the United States are F1 (=1 if the physician were born in an English-speaking country other than the United States or in a Northern or Western European country); and F2 $(=1$ if the physician were born in the rest of Europe, or in an Asian, African, or Latin American country). Some patients and referring physicians seem to consider medical education obtained abroad to be inferior, and this factor may consequently be reflected in earnings of foreign physicians. In addition, foreign physicians may experience language difficulties or be subject to racial or ethnic discrimination. For these reasons the coefficients of both $\mathrm{F} 1$ and F2 are expected to be negative, but the coefficient of $\mathrm{F} 2$ is expected to be much more so. ${ }^{5}$

Employment type variables distinguish between self-employed and salaried physicians and between full-time and part-time work. Salaried physicians are expected to earn less per unit of time (lower wages), because they have more regular hours, treat more "interesting" (serious) cases, have greater contact with peers, and engage in fewer entrepreneurial functions. Dummy variables for physicians primarily employed by private companies (including voluntary hospitals and private medical schools) and governments have been included (W1 and W2). About oneseventh of the physicians in the samples are primarily self-employed but also receive some earnings from an employer. The expected influence of the variable that identifies these physicians (W3) is negative, but less so than the variables identifying fully salaried physicians.

Physicians working fewer than fifteen hundred hours per year are considered to be active on a part-time basis $(\mathrm{PT}=1)$. There are several reasons for expecting a partial effect of part-time work on physician wages. First, the Census Bureau includes sick leave pay

5If the location of medical school were the only factor, a dummy variable representing location of medical school would be far superior to one for the physician's birthplace. That information, however, is not available from the census, and since language and discrimination are also potential influences on wages, F1 and F2 are reasonably satisfactory choices. 
as wage and salary income, thus raising the hourly wage. Second, as indicated above, the marginal hourly physician wage varies inversely with the length of the workweek. Since the marginal wage declines slowly as physician hours per week increase, the marginal wage may be considered nearly constant for small differences in workweek length, but the marginal hourly wage should be considerably higher for part-time physicians. On the other hand, since the weekly wage reflects workweek length as well as the hourly wage, it is not possible to predict the sign of PT's coefficient in the weekly wage equation. ${ }^{6}$

All other explanatory variables pertain to the characteristics of the geographic area in which the physician is located. Some of these correspond to the physician's type of community (urban or rural) within a particular state. Others refer only to the physician's state. If the physicians' services market were in competitive equilibrium and if there were no nonpecuniary differences in alternative locations, area variables would exert no independent effect on wages. Demand differences would be accompanied by differences in relative physician supply, and demand schedule shifts would be fully offset by physician exit and entry. But available evidence suggests that this market is not competi-

\footnotetext{
6There are substantial interspecialty differences in physician earnings. It would have been desirable to include specialty in the wage equations, but unfortunately the census does not collect these data. By contrast, there is virtually no interspecialty variation in weeks and hours. See Steve G. Vahovich, ed., Profile of Medical Practice (Chicago: Center for Health Services Research and Development, American Medical Association, 1973). Dr. Vahovich includes physician specialty in a forthcoming analysis of physician hours and weeks of work which uses AMA data.
}

tive, ${ }^{7}$ and that all geographic areas are not equally attractive. Thus, differences in earnings that reflect area demand and supply variables are likely to exist. Median income in the area (MEDY) and the percent of the state population with some basic surgical and medical insurance coverage (SURG and MED) represent patient ability to pay for medical services. The percentages of population in the physician's area under age five (ALT5) and over age sixty-four (AGT65), and the number of restricted activity days per capita population (RAD) represent patient medical need. ${ }^{8}$ Finally, holding community demand constant, individual physicians in physician-rich areas experience less demand for their services; physicians per 10,000 state population (MDPOP) measures this factor.

\section{Supply Equation Specification}

Following the calculation of wages, two supply equations will be estimated, in which the dependent variables are the number of weeks worked during the year before the census and the number

7See Joseph P. Newhouse and Frank A. Sloan, "Physician Pricing: Monopolistic or Competitive: Reply," Southern Economic Journal, Vol 38, No. 4 (April 1972), pp. 577-80.

8MEDY, ALT5, and AGT65 refer to the urban or rural area of the state in which the physician resides. SURG, MED, RAD, and MDPOP refer to the physician's state. Restricted activity days (RAD) refer to days during which a person's activity is limited in some respect because of illness. It is possible that the parameter estimates of the area variables are biased toward zero because the geographic area encompassed by the variable is larger than the physician's market area. To test for potential biases, the 1960 observations have been aggregated into states, and wage regressions have been run with the state as well as the individual physician as the observational unit. Many of the results of the micro and aggregated regressions (presented in Sloan, "A Microanalysis of Physicians' Hours") are remarkably similar, and there is no evidence of systematic bias. 
of hours worked during the reference week. Judging from simple correlations (0.21 in 1960 and 0.18 in 1970), these two supply variables are only weakly related to each other. The weak correlations should serve as a warning that no single variable may appropriately be used as an indicator of physician supply behavior.

The independent variables, each of which is defined in the Appendix, fall into six groups: (1) wage and income; (2) age and ethnicity; (3) employment type; (4) household charactertistics; (5) disability status; and (6) area charactertistics.

Central to the supply analysis are the wage and income variables. An increase in the wage rate increases the cost of time not devoted to market activities, thereby encouraging market work-the substitution effect. However, the higher wage also results in a higher income, leading to increased demand for commodities, one of which is nonmarket time-the income effect. The sign of the coefficient cannot therefore be predicted a priori, since it depends on the relative strength of the positive substitution effect and the negative income effect. Both linear variables (WAGEEW in the weeks and WAGEEH in the hours equation) and squared wage variables are included; the latter permit the supply curve to bend backward after a certain wage level is reached. ${ }^{9}$

\footnotetext{
9The part-time dummy variable PT has been set equal to zero in all cases for purposes of generating the predicted wage series, WAĜEW and WAĜEH. Since PT reflects weeks and hours of work, the variable is not independent of the supply equations' error terms. It is included in the wage generating equation because otherwise certain coefficients (such as those for age) would be likely to reflect physician part- or full-time status. PT is not excluded from the wage predictions in Sloan, "A Microanalysis of Physicians' Hours."
}

An increase in nonemployment income theoretically has a negative impact on weeks and hours of work. The nonemployment income variable (Y) used in this study is the sum of property income accruing to the physician and his spouse plus earnings of children and other persons living in the physician's household. The variable $\mathrm{Y}$ serves an important role in the supply equation since Y's parameter estimate can be used to infer responses to income totally unrelated to the physician's degree of effort in the marketplace. Unfortunately, however, measured $\mathrm{Y}$ may partially reflect past earnings of the physician. Some previous studies have adjusted property income data in an attempt to derive a measure that does not reflect past earnings. Similar adjustments are not feasible in the present study. ${ }^{10} \mathrm{~A} \mathrm{Y}^{2}$ term is also included in the supply equation to test for nonlinear effects.

Earnings of the physician's spouse are measured by YS. If nonmarket time of the physician and that of his spouse are substitutes, the parameter estimate on YS should be more negative than Y's, because YS would then incorporate a negative cross-substitution effect in addi-

\footnotetext{
10See David H. Greenberg and Marvin Kosters, Income Guarantees and the Working Poor: The Effect of Income Maintenance Program on the Hours of Work of Male Family Heads (Santa Monica, Calif.: Rand Corp., 1970 (R-579OEO)); Robert T. Michael, "Dimensions of Household Fertility: An Economic Analysis." 1971 Proceedings of the Social Statistics Section of the American Statistical Association, pp. 12636; Michael Grossman and Lee Benham, "Health, Hours, and Wages," in Perlman, ed., The Economics of Health and Medical Care, pp. 205-33. The adjustments referred to in the text are based on such exogenous variables as work experience, but in this study it was impossible to find data on any such variables that were not already present in the wage equation. Thus, parameter estimate inefficiency arising from multicollinearity would have largely offset any potential advantages of the adjustment.
} 
tion to the "pure" income effect common to the two variables. Conversely, if nonmarket time of physician and that of his spouse are complements, the crosssubstitution effect should be positive, and the YS parameter estimate should be less negative than Y's. It follows if nonmarket time of physician and that of his spouse are independent, $Y$ and YS parameter estimates should be identical in both sign and magnitude.

As individuals age, the physician's personal return to further asset accumulation diminishes. Physicians in the higher age groups therefore may be expected to work less. Parameter estimates of variables A2 through A5 should have positive signs, but they may be expected to decrease monotonically as the physician grows older. Moreover, as BenPorath demonstrates, more on-the-job training may be expected to occur during the earlier years. ${ }^{11}$ Time spent by included in the hours dependent variable. This factor reinforces the expected pattern with respect to age. The variables F1, F2, and RACEN measure differences in work preferences that might by associated with differences in ethnicity.

Employment type variables have a role in the supply as well as the wage equations. There is substantial evidence indicating that salaried physicians spend less time in market work than their selfemployed colleagues. ${ }^{12}$ In part, this pattern may reflect the fact that the marginal financial return to effort (in terms

\footnotetext{
11Yoram Ben-Porath, "The Production of $\mathrm{Hu}$ man Capital Over Time," in W. Lee Hansen, ed., Education, Income, and Human Capital (New York: Columbia University Press, 1970), pp. 129-51.

12This literature is summarized in Frank A. Sloan, "The Effect of Incentives on Physician Practice Performance," in John Rafferty, ed., Health Manpower Productivity (Lexington, Mass.: D.C. Heath, 1974).
}

of hours or effort per hour) beyond a certain minimum may be zero. If this is the case, the wage measures (WAĜEW and WAĜEH) will overstate the return to the salaried physician at the margin, even though dummy variables distinguishing salaried from self-employed physicians have been included in the wage equation. Including the variables for fully salaried physicians (W1 and W2) in the supply equations compensates for the overstatement of the relevant wage. A negative sign on the $\mathrm{Wl}$ and W2 coefficients may reflect another factor as well: salaried physicians may simply have a greater aversion to long work hours and for that reason may have opted for salaried practice where there is less pressure on physicians to work more hours than they desire.

Given society's value system, females are generally recognized to be more productive than males in household work. The expected sign of SEX is thus negative. The presence of children in the household is generally held to raise the wife's productivity in the household relative to the husband's. Additional children also generate an income effect since the family becomes poorer on a per capita basis. Both effects imply that the male physician with children should spend more time in the market if the spouse is present. The direction of impact for the female physician with children is likely to be the opposite of her male physician peers. To account for the impact of these variables, C1 $\quad(=1$ if there are childen under age two) and C2 ( $=1$ if there are children over age two in the household) are included regardless of the sex of the physician parent. If the physician is both female and a parent of a child less than age two, both $\mathrm{SD} \cdot \mathrm{Cl}$ and $\mathrm{Cl}$ equal one. If the physician is female and has a child age 
two and over, both SD $\cdot \mathrm{C} 2$ and $\mathrm{C} 2$ equal one. These latter variables permit differential responses for male and female physicians. Married physicians are distinguished by the dummy variable MR (=1 if physician is married).

The 1970 Census of Population requested information on disability status. Respondents between the ages of fourteen and sixty-four were asked if they had a health condition or disability limiting the type or amount of work they could perform, or both, and whether poor health prevented them from doing any work at all. Variables based on these questions performed quite poorly in early phases of the empirical work and were thus excluded from the regressions reported below.

Finally, two area characteristics variables are included. Physicians in warmer climates may have greater opportunities for outdoor recreation and may thus spend less time in market activities. A climate variable (CLM), defined in terms of the number of degree days, has been included in the supply equation. ${ }^{13}$ The expected sign of CLM's coefficient is positive.

Medical ethics dictate that a physician treat patients in need of medical services if such services are not available from another source. In geographic areas with a low physician-to-population ratio, individual consumers have relatively few alternative sources of medical care. Physicians will therefore be forced to work

\footnotetext{
13Definition of a degree day: "A unit, based upon temperature difference and time, used in estimating fuel consumption and specifying nominal heating load in the winter. For any one day, when the mean temperature is less than $65^{\circ} \mathbf{F}$, there exist as many degree days as there are Fahrenheit degrees difference in the temperature between the average temperature for the day and $65^{\circ}$ F." U.S. Department of Commerce, Statistical Abstract of the United States, 1970, p. 160.
}

longer and more irregular hours in such areas. The variable MDPOP should have a direct, negative impact on physician effort. After insignificant coefficients were obtained in the weeks equation in early phases of the research, however, MDPOP was dropped from that equation. ${ }^{14}$

\section{Empirical Results: Wage-Generating Equations}

Table 1 presents estimates of the wagegenerating equations for both weekly and hourly earnings. Although many of the parameter estimates are similar in both years, $\mathrm{F}$ tests for regression coefficient homogeneity on both equations reject the null hypothesis that the relationships are the same in both years at the one percent significance level. The $\mathrm{R}^{2} \mathrm{~s}$ are low, as is common in regression analysis with micro data, but the majority of parameter estimates are significant at the 5 percent level or better. Over two-thirds of the pooled 1960-70 wage equation parameter estimates (not shown) are significant.

Age and experience variables are generally significant. The parameter estimate for the dummy variable indicating that the respondent has been a physician for less than five years (NMD) is significant in both weekly and hourly wage equations. With NMD included in 1970 data, the coefficient of A2 (representing physicians age thirty to thirty-nine) falls substantially. In all four regressions, wages are highest for M.D.s in their forties (A3). As expected, the migration variable (M) exerts a negative impact on both types of wages.

The variable SEX (=1 for female

14 Other insignificant variables have not been excluded. The physician-population ratio, however, proved to be highly collinear with other explanatory variables as well as being insignificant. 


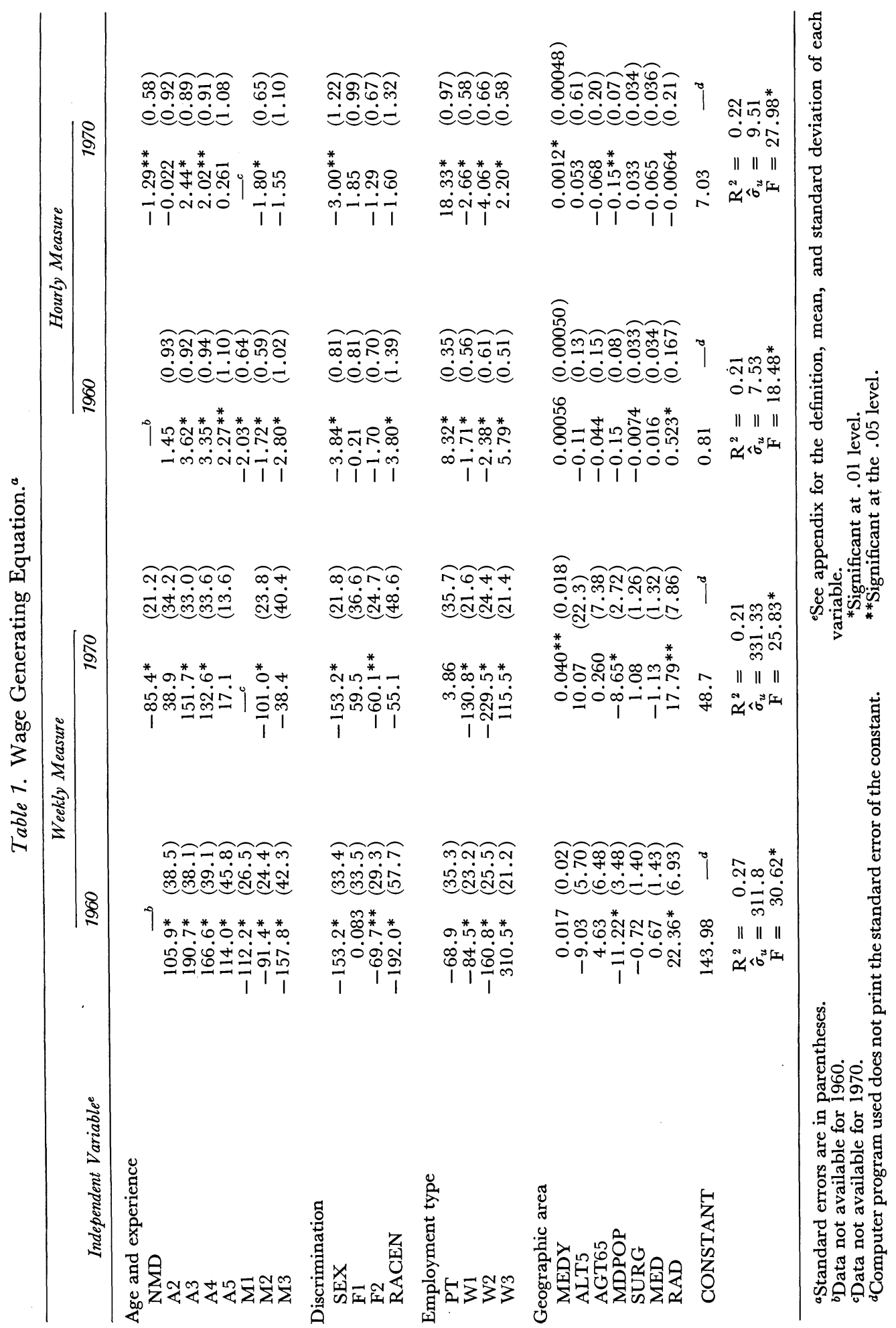


physicians), the first of the discrimination variables, enters significantly at the 5 percent level or better in both equations. In both 1960 and 1970, female physicians earned $\$ 153.20$ less per week than males, ceteris paribus; ${ }^{15}$ on an hourly basis, they earned $\$ 3.84$ less than males in 1960 and $\$ 3.00$ less in 1970 . Since the mean wage for all physicians in the sample increased between the two years (in real terms), one may conclude that female physician earnings improved relative to the mean during the decade of the 1960s. The foreign variable $\mathrm{F} 2$ also generally enters significantly, ${ }^{16}$ and its coefficients are also less negative for 1970 than for 1960. A similar pattern, but even more pronounced, holds for RACEN: the 1960 parameter estimates are significant at the one percent level, whereas the 1970 estimates are only slightly larger than their standard errors. The number of black physicians in both samples is small (31 and 55), but since the sample size is larger in 1970 than in 1960 , the less precise 1970 coefficient cannot be attributed to sample size. Finally, note that $\mathrm{Fl}$ is the only discrimination variable that does not yield significant coefficients for either year. Those for 1970 are positive, probably reflecting the fact in part that the majority of F1 physicians came to the United States long before 1960. By 1970, their practices were well established, and any disadvantages caused by foreign birth had been eliminated.

Virtually all employment type variables have a significant effect on wages. Physicians with private (Wl) and gov-

151970 wages are expressed in 1960 dollars. We have verified these coefficients, which were surprising because of their identical values in both years.

16 The F2 parameter estimate is significant at the one percent level in pooled (1960-1970) regressions for both weekly and hourly wages. ernment (W2) employers earn less on the average than do self-employed physicians, and the relative earnings position of these employed physicians deteriorated during the 1960s. On the other hand, semi-employed physicians with some earnings from employment sources (W3) earn more than physicians whose earnings are solely from self-employment. One may speculate that the W3 physicians possess special skills that are highly compensated on both salaried and selfemployed bases, or perhaps they realize a high return from working unpopular hours for an employer. PT's coefficient is positive in the hours equation, as expected, but its magnitude, particularly in 1970, is surprisingly high. In both weekly wage equations, PT parameter estimates are insignificant.

Among area characteristics variables, the physician-population ratio (MDPOP) and restricted activity days per capita population (RAD) are generally significant with the expected signs. Median income (MEDY) exerts a positive and significant impact on wages in 1970 , but not in 1960; it also enters significantly in pooled weekly and hourly wage regressions (not shown). Neither the age coefficients (ALT5 and AGT65) nor the insurance coefficients (SURG and MED) are significant in the Table 1 regressions. Pooling 1960 and 1970 data greatly improves the performance of the medical insurance variable (MED). The MED coefficient in the pooled weekly wage regression has the expected sign and is significant at the 5 percent level.

\section{Empirical Results: Supply Equations}

Tables 2 through 4 contain results of the weeks and hours supply regressions. On the basis of $\mathbf{R}^{2} \mathbf{s}$ and significance tests, the supply regressions are less satisfactory than those for wages. $F$ tests for regres- 


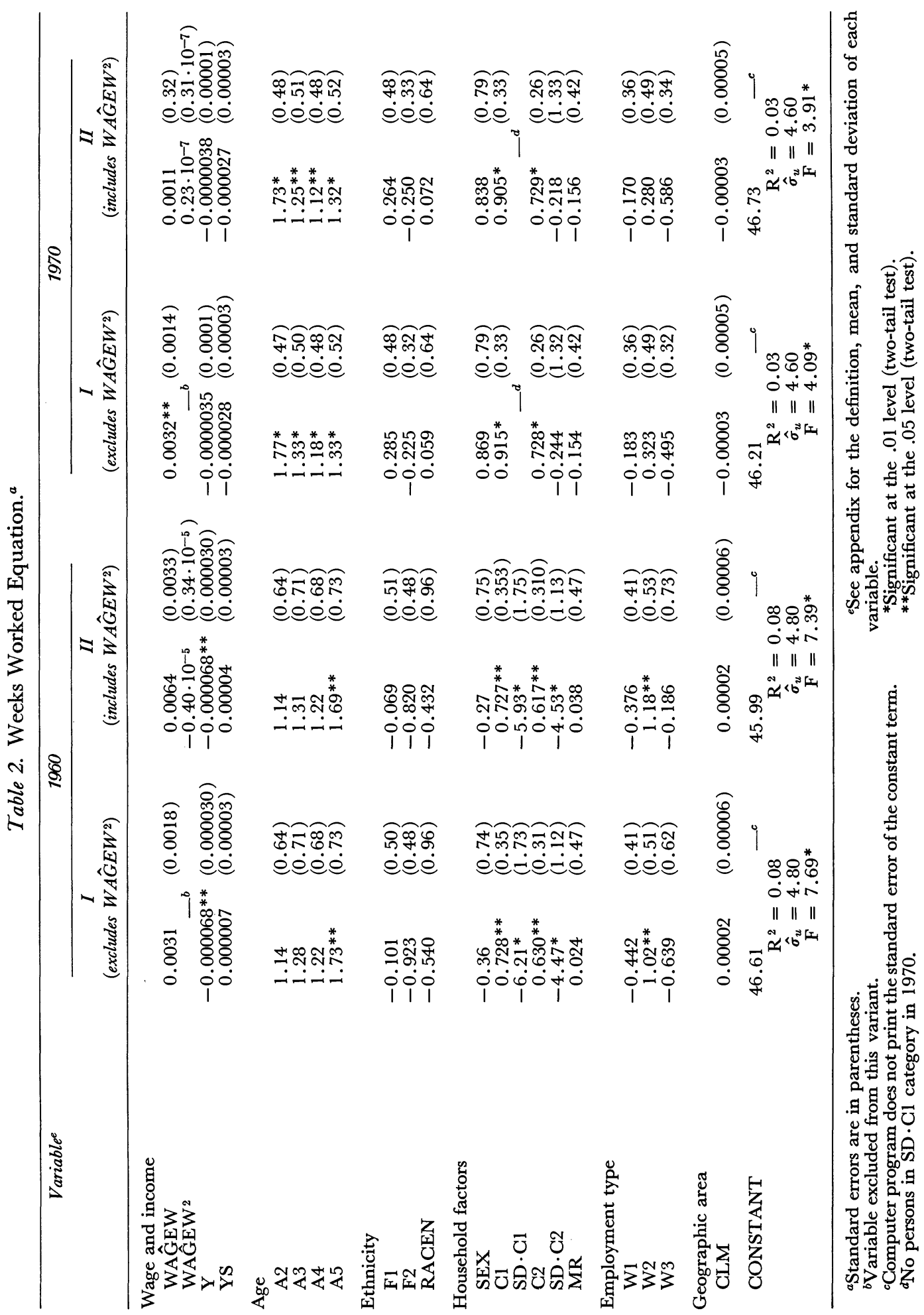


sion coefficient homogeneity reveal 19601970 structural changes at the 5 percent level in the weeks equation. During the same period, the hours relationship exhibits more stability; the null hypothesis (no structural change) is rejected at the 10 percent confidence level.

The wage coefficients in the weeks equation suggest a positive but small supply response to the weekly wage. In the variants that exclude the squared wage term (Variants I in Table 2), the wage coefficient is significant at 10 percent in 1960 and 5 percent in $1970 .{ }^{17}$ There is evidence of a backward-bending supply curve for weekly wages of eight hundred dollars or more in 1960 (approximately one standard deviation above the mean for that year). At that point, the negative effect of the squared wage term begins to outweigh the positive effect of the linear term. On the other hand, the squared wage term enters the 1970 weeks regression with a positive sign, and both 1970 wage parameter estimates become highly insignificant when the squared wage term is added (Variants II in Table 2). Also, the weeks supply response to wages is low as indicated by elasticities (at the mean) of less than 0.1 . The results for the two years are not contradictory, however, since the negative supply response to the weekly wage applies only to a minority of 1960 physicians in the upper tail of the physician wage distribution.

Table 3 shows that the measured response of hours to the hourly wage is sensitive to equation specification, with differing results for the two years. Without the physician-population ratio (MDPOP) and excluding the squared wage term, the wage parameter estimates

\footnotetext{
17The coefficient in a pooled (1960-1970) regression is positive and significant at the one percent level.
}

are positive but insignificant in both years (Variants I in Table 3). With the squared wage term included (Variants II), the parameter estimates indicate both negatively and positively sloped supply functions, but not the pattern generally predicted by consumer theory according to which the linear. and squared terms are positive and negative, respectively. Sign reversals often result from multicollinearity, and in such cases, significance tests on the sums of parameter estimates are particularly instructive. $^{18}$ Tests of the derivative of hours with respect to the wage, incorporating the effects of both linear and squared wage variables, are insignificant for plausible wage levels.

With MDPOP included, and the squared wage term excluded, the wage parameter estimates in the hours regressions are negative (Variants III in Table $3)$. In 1960, the wage coefficient is significant at the 10 percent level; in 1970 , it is less than one-third the size of its standard error. Variant IV wage estimates display the same pattern as those in Variants II, but inclusion of MDPOP makes the supply response more negative. As with MDPOP excluded, tests on the derivative are insignificant for plausible values of the wage, and elasticities are low (less than 0.1 in absolute value).

Nonemployment income $(\mathrm{Y})$ has the expected negative impact in both weeks and hours equations. Its effect on weeks worked is much smaller in 1970 than in 1960. The $\mathrm{Y}$ coefficients in the hours equations suggest a similar response in both years. Results of regressions with a

\footnotetext{
1.8See Henri Theil, Principles of Econometrics (New York: John Wiley, 1971) and Jon Conlisk, "When Collinearity Is Desirable," Western Economic Journal, Vol. 9, No. 1 (December 1971), pp. 393-407. The test is an adaptation from Jan Kmenta, Elements of Econometrics (New York: MacMillan, 1971), p. 372.
} 
$\mathrm{Y}^{2}$ term included are presented in Table 4. Adding this nonlinear variable increases the supply responses to nonemployment income over the range that is relevant for most physicians. ${ }^{19}$ The 1960 weeks Y parameter estimates imply that a physician with annual nonemployment income of $\$ 10,000$ would work approximately one week less per year than a colleague, identical in all respects, except having no nonemployment income. The 1960 hours Y parameter estimates imply that a physician with $\mathrm{Y}$ of $\$ 10,000$ will spend 1.3 hours per week less in professional activities than one with no such income. Based on the 1970 hours estimates, he would work about 2 hours less.

Spouse income (YS) coefficients are insignificant in all weeks regressions. Corresponding estimates for hours equations are significant at the 5 percent level in 1960 , but not in 1970 . The relatively poor performance of the YS variable in the weeks equation is understandable. Physician and spouse leisure, at least in the weeks dimension, may be complementary. Vacations are taken by the family, and these are more difficult to schedule if the wife works. Thus, husbands of working wives may work more weeks. Off-setting this in part is the "pure" income effect of spouse earnings on physician hours, which is unambiguously negative.

The age parameter estimates are generally significant. Since the dummy varia-

\footnotetext{
19Although the $\mathrm{Y}^{2}$ parameter estimates are positive, one should probably not conclude that the impact of income on supply diminishes as $\mathrm{Y}$ increases. This term picks up work patterns of a very small percentage of the sample (around 2 or 3 percent) who remain at work although independently wealthy. Very wealthy physicians who leave medicine entirely to manage their fortunes are excluded from our sample; if they were included, the coefficient of the quadratic term would be smaller.
}

bles test behavior of physicians younger than sixty-five against those in the sixtyfive to sixty-nine age group, this result means that post-age sixty-five physicians work substantially less. In the hours equation, age coefficients decline monotonically with age, but the pattern for weeks is irregular. Time spent on professional reading and other types of continuing education is likely to be greater in the early years of practice. This is probably one reason for the observed age-related pattern with respect to hours worked per week. Estimates of hours devoted to patient care are not available from the census source.

The ethnicity variables are less important. Neither the foreign birth nor race variables are significant in the weeks equation. They are, however, significant in some variants of the hours equation.

The household characteristics variables indicate that female physicians with children perform less market work. This finding is based on significance tests on sums of the sex and children coefficients (the sum of SEX, Cl (or C2), and SD.C1 (or SD.C2)). Female physicians with children under age two (Cl) worked significantly (at the one percent level) fewer weeks in both 1960 and 1970. Those with children age two and over living in the household worked significantly (at the one percent level) fewer weeks in 1960, but not in $1970 .{ }^{20}$ All tests of the sums of SEX, C, and SD.C coefficients are significant at the 5 percent level or better.

Type of employment demonstrates no systematic effect on the number of weeks worked, but the salaried physician, particularly the government employee, does have a shorter workweek. The differ-

\footnotetext{
20Insignificance in 1970 may reflect small sample size. Only eighteen of 1970 physicians fall in the SD - C2 category.
} 


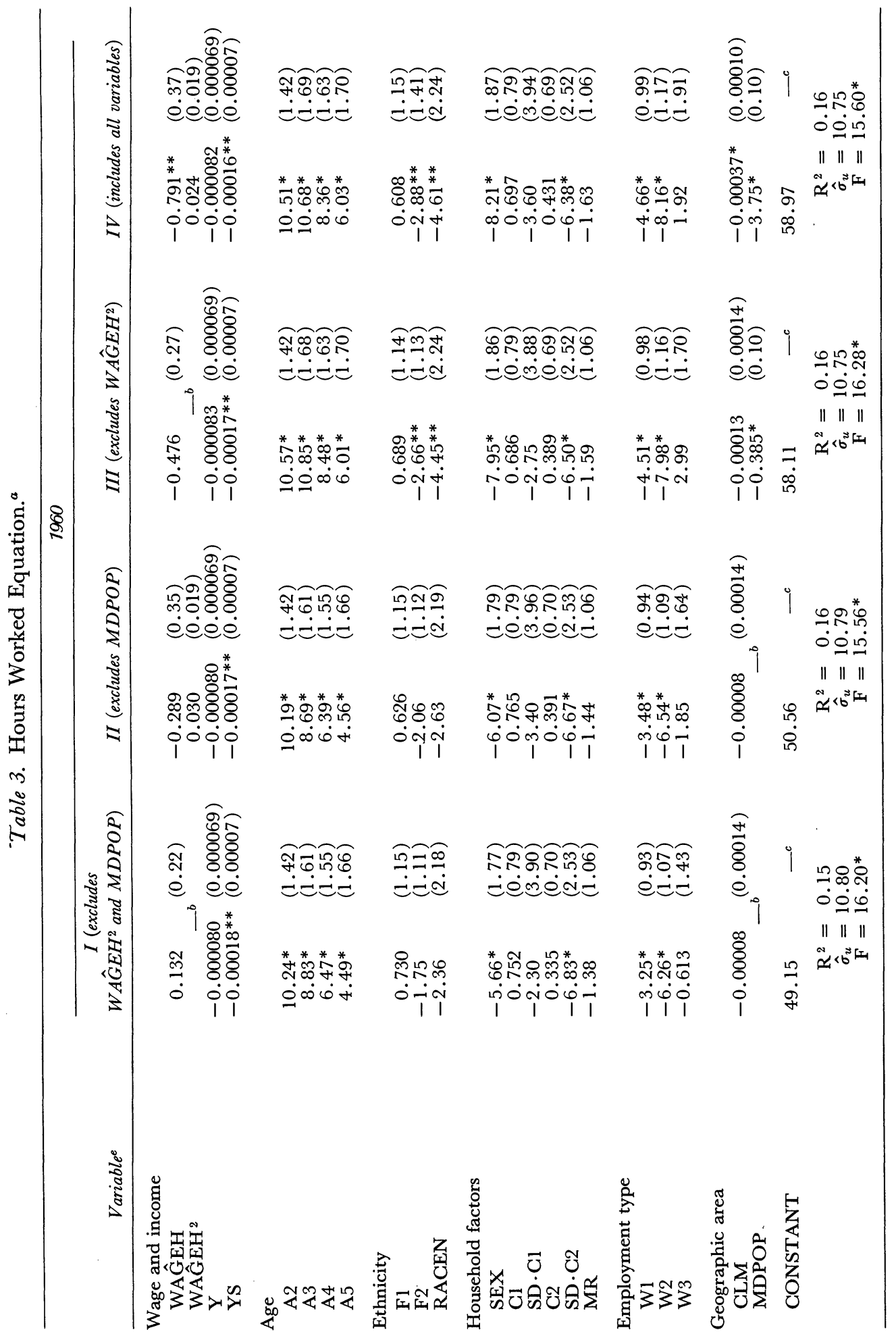


PHYSICIAN SUPPLY BEHAVIOR IN THE SHORT RUN

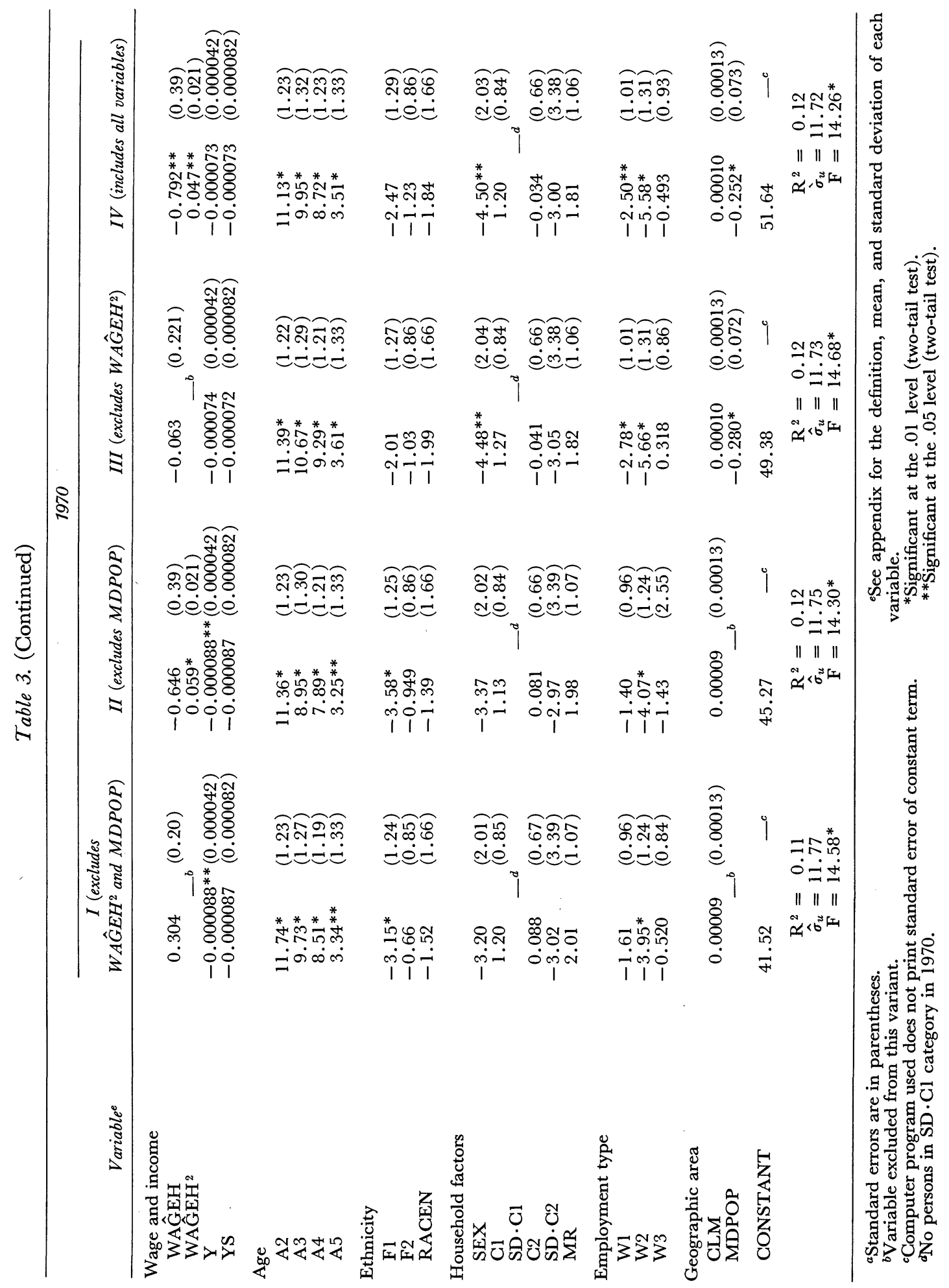


Table 4. Wage and Income Coefficients with Nonemployment Income Squared. ${ }^{a}$

\begin{tabular}{|c|c|c|c|c|c|}
\hline WEEKS & $r$ & $r^{2}$ & $r s$ & $W A \hat{G} E W$ & $W A \hat{G} E W^{2}$ \\
\hline 1960-I & $\begin{array}{r}-0.00016^{*} \\
(0.00005)\end{array}$ & $\begin{array}{l}0.31 \cdot 10^{-8} \\
\left(0.18 \cdot 10^{-8}\right)\end{array}$ & $\begin{array}{r}0.000007 \\
(0.00003)\end{array}$ & $\begin{array}{c}0.00306 \\
(0.00178)\end{array}$ & - \\
\hline 1960-II & $\begin{array}{r}-0.00015^{*} \\
(0.00006)\end{array}$ & $\begin{array}{c}0.31 \cdot 10^{-8} \\
\left(0.18 \cdot 10^{-8}\right)\end{array}$ & $\begin{array}{r}0.000005 \\
(0.00003)\end{array}$ & $\begin{array}{c}0.00620 \\
(0.00327)\end{array}$ & $\begin{array}{c}-0.0000039 \\
(0.0000034)\end{array}$ \\
\hline 1970-I & $\begin{array}{c}-0.000038 \\
(0.000036)\end{array}$ & $\begin{array}{c}0.71 \cdot 10^{-9} \\
\left(0.66 \cdot 10^{-9}\right)\end{array}$ & $\begin{array}{c}-0.000029 \\
(0.000032)\end{array}$ & $\begin{array}{l}0.00326^{* *} \\
(0.00142)\end{array}$ & - \\
\hline 1970-II & $\begin{array}{c}-0.000039 \\
(0.000036)\end{array}$ & $\begin{array}{c}0.73 \cdot 10^{-9} \\
\left(0.66 \cdot 10^{-9}\right)\end{array}$ & $\begin{array}{c}-0.000029 \\
(0.000032)\end{array}$ & $\begin{array}{r}0.000092 \\
(0.00032)\end{array}$ & $\begin{array}{r}0.000025 \\
(0.00003)\end{array}$ \\
\hline HOURS & $r$ & $r^{2}$ & $r s$ & $W A \hat{G} E H$ & $W A \hat{G} E H^{2}$ \\
\hline $1960-\mathrm{I}$ & $\begin{array}{c}-0.00024 \\
(0.00013)\end{array}$ & $\begin{array}{c}0.56 \cdot 10^{-8} \\
\left(0.41 \cdot 10^{-8}\right)\end{array}$ & $\begin{array}{c}-0.00018^{* *} \\
(0.00007)\end{array}$ & $\begin{array}{l}0.127 \\
(0.221)\end{array}$ & - \\
\hline 1960-II & $\begin{array}{c}-0.00024 \\
(0.00013)\end{array}$ & $\begin{array}{l}0.58 \cdot 10^{-8} \\
\left(0.41 \cdot 10^{-8}\right)\end{array}$ & $\begin{array}{c}-0.00017^{* *} \\
(0.00007)\end{array}$ & $\begin{array}{c}-0.303 \\
(0.348)\end{array}$ & $\begin{array}{l}0.031 \\
(0.019)\end{array}$ \\
\hline 1970-I & $\begin{array}{c}-0.00022^{* *} \\
(0.00009)\end{array}$ & $\begin{array}{l}0.30 \cdot 10^{-8} \\
\left(0.17 \cdot 10^{-8}\right)\end{array}$ & $\begin{array}{c}-0.000092 \\
(0.000082)\end{array}$ & $\begin{array}{r}0.316 \\
(0.20)\end{array}$ & - \\
\hline 1970-II & $\begin{array}{r}-0.00024^{*} \\
(0.0009)\end{array}$ & $\begin{array}{c}0.30 \cdot 10^{-8} \\
\left(0.17 \cdot 10^{-8}\right)\end{array}$ & $\begin{array}{c}-0.000092 \\
(0.000082)\end{array}$ & $\begin{array}{r}-0.657^{*} \\
(0.387)\end{array}$ & $\begin{array}{l}0.060^{*} \\
(0.020)\end{array}$ \\
\hline
\end{tabular}

${ }^{a}$ Standard errors in parentheses.

*Significant at the .01 level.

**Significant at the .05 level.

ences between the workweek of salaried and self-employed physicians appear to have diminished during the 1960s.

Judging from the Table 3 estimates, the physician-population ratio (MDPOP) exerts a significantly negative impact on physician work hours. Climate (CLM), the second of two area characteristics variables, demonstrates no impact on supply.

\section{Other Studies}

Previous studies by Feldstein and by Fuchs and Kramer suggest that the supply curve of physicians' services is backward-bending. ${ }^{21}$ Feldstein's conclusion

\footnotetext{
21See Martin S. Feldstein, "The Rising Price of Physicians' Services," The Review of Economics and Statistics, Vol. 54, No. 1 (May 1970), pp. 121-33 and Victor Fuchs and Marcia Kramer, Determinants of Expenditures for Physicians' Services in the United States (Washington: United States Department of Health, Education, and Welfare, 1972) .
}

follows from ordinary least squares regressions of a measure of the quantity of services provided per physician on a measure of the average physician fee and other independent variables, using aggregate (United States) observations for nineteen years. His estimates of the elasticity of supply with respect to the average fee range from -1.91 to -0.28 . Standard errors of the fee coefficients are frequently large. Corresponding elasticities in the Fuchs and Kramer study, based on data from thirty-three states, range from -0.83 to 0.01 . Fuchs and Kramer use two-stage least squares, and their fee parameter estimates are also imprecise.

In a comment on the Feldstein article, Brown and Lapañ present a supply-ofphysician-services equation with a somewhat differently specified dependent variable and some changes in the inde- 
pendent variables. They obtain a significantly positive supply response to the customary physicians' fee. ${ }^{22}$ The average fee variable used by Feldstein and by Fuchs and Kramer is preferable to the customary fee measure, but one should not attribute the sign reversal in Brown and Lapan's study solely to their different specification of the fee variable. Given the varying signs and imprecise fee parameter estimates obtained in these studies, it is apparent that little is currently known about the slope of the supply function for physicians' services.

The present'study uses weeks and hours of work, not a measure of the quantity of physicians' services actually provided per physician, as the dependent variable. A backward-bending supply curve for physician hours or weeks would provide a very plausible mechanism for a backward-bending physicians' services curve. On the other hand, if the supply curve for physician time has a postive slope, it would still be theoretically possible for the physicians' services supply curve to be backward-bendingbut as a practical matter such a relationship would be very difficult to explain. For example, it is doubtful that the labor supply functions for other categories of medical personnel are negatively sloped, since most of these employees are female and econometric supply functions for females uniformly have positive slopes. ${ }^{23}$ Possibly, as recent

\footnotetext{
22Douglas M. Brown and Harvey E. Lapan, "The Rising Price of Physicians' Services: A Comment," The Review of Economics and Statistics, Vol. 54, No. 1 (February 1972), pp. 101-05.

23On nurse supply functions, see Lee Benham, "The Labor Market for Registered Nurses," The Review of Economics and Statistics, Vol. 53, No. 3, pp. 246-52 and Mario Bognanno, Jesse Hixson, and James Jeffers, "The Short-Run Supply of Nurses' Time," The Journal of Human Resources, Vol. 9 ,No. 1 (Winter 1974), pp. 80-94.
}

work by Reinhardt suggests, the physician incurs psychic costs when he hires aides, and these psychic costs rise with income. ${ }^{24}$ Then, to the extent that practices become less aide-intensive, fewer services might be provided than would otherwise be the case even though the physician time input supply curve is positive.

The results of this study suggest that there is a low degree of responsiveness of physician supply to wages and that the evidence to support a backward-bending supply curve for the physician labor input must be considered weak at best. Although workweek length appears to respond negatively to wages over a considerable range of wages, the parameter estimates are insignificant when evaluated at plausible wage levels. Also, the negative effect of nonemployment income is weak on both the hours and weeks dimensions of supply. A strong effect of nonemployment income might have served as a clue that the supply curve for hours and weeks is backwardbending, ${ }^{25}$ but clearly the variable's impact is too small to suggest this.

\section{Policy Implications}

As noted in the introduction, empirical analysis of the physician supply curve has a bearing on several public policy issues. One of these is price control. It is generally accepted that price control

\footnotetext{
24Reinhardt, "A Product Function for Physician Services."

25Income and pure substitution effect calculations are available from the author upon request. One might argue that the $\mathrm{Y}$ parameter estimates presented in the tables are biased toward zero because the series is not fully independent of effort or of errors in measurement. Analysis of nurse hours of work by the author with the 1960 Census Public Use Sample, using the same variable $\mathrm{Y}$, produces a much higher income effect. The higher coefficient for nurses suggests that nonemployment income is not poorly measured by the census in general.
} 
regulations imposed during the early 1970s greatly reduced the rate of physician fee inflation. Between 1971 and 1973 , for example, fees rose at a far lower rate than at any time during the preceding decade. ${ }^{26}$ To the extent that fees are reflected in the physician wage, price control might have had a positive, zero, or negative impact on the physician time input. The results of the present study suggest on balance that the effect of price control on the time physicians are willing to devote to their practices is negligible.

Government health insurance programs have infused substantial amounts of funds into the health services sector. One consequence has been an increase in physicians' earnings. It would be unfortunate if the very efforts of policymakers to guarantee access to medical services to disadvantaged groups had simultaneously created a disincentive for physicians to devote time to their profession. In this respect, the low supply elasticity estimates of this study are reassuring. It is doubtful that such federal programs as Medicare and Medicaid have reduced the physician time input, nor is a national health insurance program likely to do so, at least in the short run. On the other hand, the results of this study certainly do not rule out different responses to increased earnings over the long run, such as those relating to the choice of medicine as an occupation, the choice of a specialty within medicine, and the choice of a location in which to practice.

Employed physicians (excluding interns and residents) have grown in number relative to self-employed physicians. Although the results presented here are somewhat ambiguous with respect to

26B. S. Eisenberg, Socioeconomic Issues of Health (Chicago: American Medical Association, 1974), pp. 49-54. weeks, those for hours are not. On balance, employed physicians devote less time to professional activities. Whether or not these work patterns reflect a systematic response to financial incentives cannot be determined with the data available for this study. The possibility remains that physicians with a preference for shorter workweeks opt for employed practice and that this segment would not be responsive to financial incentives even if they were offered. But the result serves to suggest that government efforts to promote large-scale institutional practices in which the physician is likely to be employed (rather than self-employed), although perhaps desirable for a number of reasons, may well lead to a decline in the average time input per physician.

The age parameter estimates on the whole indicate that effective supply decreases monotonically with increases in age. Medical schools have expanded enrollments rapidly in recent years. As a result, the mean age of the physician stock has declined somewhat. Since younger physicians work longer, effective supply in the aggregate may be expected to increase as mean physician age decreases. Offsetting this is a slight decrease in supply per physician resulting from increases in the physician-population ratio.

Society has placed increasing emphasis on equal career opportunities for women in recent years. This policy is certainly viewed as desirable in terms of equality of opportunity and, given the propensity of women to enter primary care specialties (such as pediatrics), the policy may be attractive in terms of promoting patient access to medical services as well. But, on the negative side, the results of this study indicate a partial withdrawal from the work force by female physicians 
with children; also, if physicians not participating in the labor force had been included, this effect would have probably beên more pronounced. Thus, assuming that women do not retire later than men, a policy designed to attract women to medicine will tend to lower the mean number of hours supplied by physicians over the life cycle.

Although physician health was hypothesized to be a supply determinant, no impact was evident from the regressions. Possibly the variables used are poor measures of health status, or perhaps health status affects supply dimensions other than the two covered by this study.

Physicians' wage equations were developed as a step in the analysis of supply behavior, but some findings from these equations have policy implications in their own right. Physicians' earnings (weekly and hourly) tend to be lower in geographic areas where physicians are numerous and where the population is relatively healthy. The negative sign on the physician-population ratio variable is of particular interest, given some previous evidence that the ratio exerts a positive impact on physicians' fees. ${ }^{27}$ Viewed in isolation, the positive physician-population coefficient in a fee re-

27See, in particular, Joseph P. Newhouse, “A Model of Physician Pricing," Southern Economic Journal, Vol. 37, No. 2, (October 1970), pp. 174-83. gression may suggest that physicians set fees to achieve a net income target. That is, as the physician-population ratio rises, demand for the services of individual physicians falls and physicians raise fees to recoup their losses. But if this were the case, the partial effect of the physician-population ratio on earnings should have been zero, not negative. This finding has an important bearing on physician manpower policy, since if the target income hypothesis were valid, which appears not to be the case, efforts to expand medical student enrollments would be inflationary. ${ }^{28}$ Judging from our result on the physician-population ratio, higher ratios temper rather than exacerbate physician fee inflation.

The wage regressions also indicate that female physicians earn less per week and per hour than their male colleagues, and black physicians earn less than whites. These differentials may reflect discrimination, but it is also possible that females and blacks enter specialties that pay less. Unfortunately, the census data base does not contain information on physician specialty to enable us to isolate the specialty effect.

\footnotetext{
28For other evidence that the physician-population ratio has a negative impact on earnings, although the variable often enters insignificantly, see Lee Benham, Alex Maurizi, and Melvin Reder, "Migration, Location, and Remuneration of Medical Personnel: Physicians and Dentists," The Review of Economics and Statistics, Vol. 50, No. 3 (August 1968), pp. 332-47.
}

\section{Appendix}

Variable Means, Standard Deviations, and Definitions ${ }^{a}$

\begin{tabular}{lrrrrrl}
\hline & \multicolumn{2}{c}{1960} & & \multicolumn{2}{c}{1970} & \\
\cline { 2 - 3 } \cline { 5 - 6 } Variable & Mean & $\begin{array}{r}\text { Standard } \\
\text { Deviation }\end{array}$ & & Mean & $\begin{array}{c}\text { Standard } \\
\text { Deviation }\end{array}$ & Definitions \\
\hline WAGEW & 431.52 & 364.02 & $540.84^{b}$ & 392.17 & Weekly wage & \\
WAGEH & 8.16 & 8.41 & $10.79^{b}$ & 10.71 & Hourly wage \\
W & 49.43 & 4.98 & 49.48 & 4.66 & Weeks worked the year prior to the census
\end{tabular}




\section{Appendix (Continued)}

Variable Means, Standard Deviations, and Definitions ${ }^{a}$

\begin{tabular}{|c|c|c|c|c|c|}
\hline \multirow[b]{2}{*}{ Variable } & \multicolumn{2}{|c|}{1960} & \multicolumn{2}{|c|}{1970} & \multirow[b]{2}{*}{ Definitions } \\
\hline & Mean & $\begin{array}{l}\text { Standard } \\
\text { Deviation }\end{array}$ & Mean & $\begin{array}{l}\text { Standard } \\
\text { Deviation }\end{array}$ & \\
\hline $\mathrm{H}$ & 54.84 & 11.67 & 54.29 & 12.44 & Hours worked during the reference week \\
\hline SEX & 0.056 & - & 0.029 & - & Female physician \\
\hline NMD & $-^{c}$ & - & 0.174 & - & Physician in other occupation in 1965 \\
\hline A2 & 0.376 & - & 0.329 & - & Physician aged 30 to 39 \\
\hline A3 & 0.305 & - & 0.296 & - & Physician aged 40 to 49 \\
\hline A4 & 0.209 & - & 0.232 & - & Physician aged 50 to 60 \\
\hline A5 & 0.066 & - & 0.077 & - & Physician aged 60 to 64 \\
\hline A6 & 0.044 & - & 0.047 & - & Physician aged 65 to 69 \\
\hline F1 & 0.056 & - & 0.046 & - & $\begin{array}{l}\text { Physician born in English-speaking country } \\
\text { other than U.S., North or West Europe }\end{array}$ \\
\hline F2 & 0.084 & - & 0.136 & - & $\begin{array}{l}\text { Physician born outside U.S., in East or South } \\
\text { Europe, Asia, Africa, Latin America }\end{array}$ \\
\hline RACEN & 0.017 & - & 0.025 & - & Black physician \\
\hline PT & 0.049 & - & 0.049 & - & Physician works less than 1500 hours per annum \\
\hline W1 & 0.148 & - & 0.193 & - & $\begin{array}{l}\text { Physician primarily employed by private } \\
\text { company }\end{array}$ \\
\hline W2 & 0.114 & - & 0.134 & - & Physician primarily employed by government \\
\hline W3 & 0.152 & - & 0.163 & - & $\begin{array}{l}\text { Physician primarily self-employed, but receives } \\
\text { some earnings from an employer }\end{array}$ \\
\hline M1 & 0.094 & - & $-^{d}$ & - & $\begin{array}{l}\text { Physician lived in another county five years } \\
\text { prior to the census }\end{array}$ \\
\hline M2 & 0.132 & - & 0.201 & - & $\begin{array}{l}\text { Physician lived in another state five years prior } \\
\text { to the census }\end{array}$ \\
\hline M3 & 0.044 & - & 0.054 & - & $\begin{array}{l}\text { Physician lived abroad five years prior to the } \\
\text { census }\end{array}$ \\
\hline $\mathbf{Y}$ & 1475.99 & 3789.62 & $2214.69^{b}$ & 11.64 & Physician nonemployment income \\
\hline YS & 873.61 & 4048.51 & $877.23^{b}$ & 3095.36 & Earnings of physician's spouse \\
\hline Cil & 0.156 & - & 0.122 & - & $\begin{array}{l}\text { Physician has children under age two in } \\
\text { household }\end{array}$ \\
\hline $\mathrm{SD} \cdot \mathrm{Cl}$ & 0.006 & - & 0 & - & Physician parent of child under age two is female \\
\hline C2 & 0.653 & - & 23 & - & Physician has children over age two in household \\
\hline $\mathrm{SD} \cdot \mathrm{C} 2$ & 0.023 & - & 0.008 & - & Physician parent of child over age two is female \\
\hline MR & 0.918 & - & 0.904 & - & Physician is married \\
\hline MEDY & 3027.27 & 433.01 & $3403.12^{b}$ & 318.68 & $\begin{array}{l}\text { Median income for the physician's geographic } \\
\text { area }\end{array}$ \\
\hline ALT5 & 11.26 & 1.53 & 8.35 & 0.53 & $\begin{array}{l}\text { Percent of population in the physician's geo- } \\
\text { graphic area under age } 5\end{array}$ \\
\hline AGT65 & 9.15 & 1.39 & 9.79 & 1.64 & $\begin{array}{l}\text { Percent of population in the physician's geo- } \\
\text { graphic area over age } 65\end{array}$ \\
\hline MDPOP & 54 & 3.28 & 14.77 & 3.93 & Physicians per 10,000 state population \\
\hline SURG & 68.84 & 10.99 & 79.3 & 12.4 & $\begin{array}{l}\text { Percent of state population with surgical } \\
\text { insurance coverage }\end{array}$ \\
\hline MED & 50.89 & 12.08 & 68.6 & 13.4 & $\begin{array}{l}\text { Percent of state population with medical } \\
\text { insurance coverage }\end{array}$ \\
\hline $\mathrm{RAD}^{e}$ & 15.93 & 1.50 & 16.07 & 1.49 & $\begin{array}{l}\text { Restricted activity days per capita state popula- } \\
\text { tion }\end{array}$ \\
\hline
\end{tabular}




\section{Appendix (Continued)}

Variable Means, Standard Deviations, and Definitions ${ }^{a}$

\begin{tabular}{|c|c|c|c|c|c|}
\hline \multirow[b]{2}{*}{ Variable } & \multicolumn{2}{|c|}{1960} & \multicolumn{2}{|c|}{1970} & \multirow[b]{2}{*}{ Definitions } \\
\hline & Mean & $\begin{array}{l}\text { Standard } \\
\text { Deviation }\end{array}$ & Mean & $\begin{array}{c}\text { Standard } \\
\text { Deviation }\end{array}$ & \\
\hline CLM & 4508.30 & 1876.13 & 4340.87 & 1967.86 & $\begin{array}{l}\text { Climate variable defined in terms of the number } \\
\text { of degree days }\end{array}$ \\
\hline
\end{tabular}

${ }^{a}$ Number of observations, 1960: 1800 and 1970: 2207.

${ }^{b} 1970$ measure is in 1960 dollars.

${ }^{c}$ Data on this variable not available for 1960 .

$d$ Data on this variable not available for 1970 .

${ }^{e}$ Data on this variable pertain to $1962-64$. The same series is used for both the 1960 and 1970 wage regressions. 